\title{
Hubungan Antara Dukungan Suami Dengan Pelaksanaan Kelas Ibu Hamil Di Puskesmas Turi
}

\author{
Kustini $^{1}$, Husnul Muthoharoh ${ }^{2}$ \\ 1,2Program Studi D III Kebidanan Universitas Islam Lamongan \\ Email : $\underline{\text { Custiniwil@gmail.com }}$
}

\begin{abstract}
ABSTRAK
Pendidikan pada Kelas ibu hamil merupakan fasilitas belajar kelompok yang mencakup tentang proses kehamilan, proses persalinan, nifas, perawatan bayi dan lain-lain, tetapi pada pemanfaatan kelas ibu hamil masih rendah. Penelitian ini bertujuan untuk mengetahui hubungan antara Dukungan Suami dengan Pelaksanaan kelas Ibu Hamil dipuskesmas Turi kabupaten Lamongan tahun 2019

Desain penelitian survei sampel ini adalah cross sectional menggunakan pendekatan kuantitatif dengan jumlah sampel 110 ibu hamil secara systematic random sampling. Analisis data meliputi análisis univariat, bivariat (chi-square) dan multivariat (poisson regresi).

Hasil analisis bivariat menunjukkan bahwa ada pengaruh antara dukungan suami p-value : $0,00<\alpha 0,05$ dengan partisipasi ibu mengikuti pelaksanaan kelas ibu hamil di Puskesmas Turi Kabupaten Lamongan.

Kesimpulan ada hubungan antara dukungan suami dengan pelaksanaan kelas Ibu hamil, Upaya peningkatan dukungan suami untuk mengikuti pelaksanaan kelas ibu hamil dengan meningkatan pengetahun suami serta meningkatkan semua komponen pendukung pelaksanaan kelas ibu hamil di Kota Lamongan.
\end{abstract}

Kata kunci : Dukungan Suami, pelaksanaan kelas ibu hamil

\section{ABSTRACT}

Education in the expectant mothers class is a group learning facility which includes about the process of pregnancy, childbirth, nifas, baby care and others, but the use of pregnant women's classes is still low.This research aims to determine the relationship between husband support and the implementation of expectant mothers Dipuskesmas in Lamongan District year 2019

Design Research survey This sample is cross sectional using quantitative approach with Sample number 110 Pregnant women systematic random sampling.Data analysis includes análysis of univariate, bivariate (Chi-square) and multivariate (regression poisson).

Results of bivariate analysis showed that there is an influence between the support of P-value husband: $0.00<\alpha 0.05$ with the participation of mothers following the implementation of the class of expectant mothers in Puskesmas of Lamongan Regency. 
Conclusion there is a relationship between husband's support with the implementation of the class of pregnant women, efforts to increase support of the husband to follow the implementation of the class of pregnant women by improving the husband's knowledge and enhancing all supporting components Expectant mothers in Lamongan city.

Keywords: Husband Support, class implementation of pregnant women

\section{PENDAHULUAN}

Pendidikan Kelas ibu hamil merupakan sarana belajar kelompok yang membahas tentang kehamilan, persalinan, nifas, perawatan bayi dan lain-lain, namun pada pemanfaatan kelas ibu hamil masih rendah. Penelitian ini bertujuan untuk mengetahui hubungan antara dukungan suami dengan pelaksanaan kelas ibu hamil dipuskesmas Turi kabupaten Lamongan tahun 2019, hubungan karakteristik ibu dan dukungan sosial suami dengan partisipasi ibu mengikuti kelas ibu hamil di Kota Lamongan tahun 2019. Kelas ibu hamil menggunakan metode partisipatif interaktif yang disertai dengan praktik seperti ceramah, tanya jawab, peragaan serta curah pendapat diharapkan mampu mengoptimalkan tingginya pengetahuan dan sikap ibu hamil untuk mempersiapkan calon orangtua dalam menjalani masa kehamilan, persalinan, perawatan bayi baru lahir dan pola asuh sebagai orangtua (Fletcher et al., 2004; Croydon, 2006; Kemenkes RI, 2011).

$$
\text { Banyak faktor yang }
$$
mempengaruhi partisipasi ibu diantaranya dukungan petugas kesehatan, sarana prasarana, motivasi pasien dan dukungan suami (Wiknjosastro, 2008). Demikian halnya dengan penelitian
Simanjuntak (2009) mengenai beberapa faktor yang dapat mempengaruhi kelengkapan pemeriksaan kehamilan ibu yaitu meliputi pendidikan, pekerjaan, penghasilan keluarga. Membangun kesadaran ibu hamil untuk berpartisipasi aktif mengikuti program kelas ibu hamil selain motivasi dari ibu diperlukan juga faktor dukungan sosial. Dukungan sosial yang ada mengara pada kenyamanan, perhatian, penghargaan atau bantuan yang diberikan orang lain atau kelompok kepada individu juga bisa didapat baik dari Suami, keluarga, maupun tenaga kesehatan (Sarafino \& Smith, 2014)..

Pelaksanaan program kelas ibu hamil di puskesmas dilakukan seminggu sekali dan minimal satu kali pertemuan di dampingi suami/keluarga. Hal ini dimaksudkan agar kesehatan ibu selama hamil, bersalin, nifas, termasuk kesehatan bayi yang baru dilahirkannya dan kebutuhan akan KB pasca persalinan menjadi perhatian dan tanggung jawab seluruh keluarga (Kemenkes RI, 2013). Penelitian Nursito (2010) membuktikan bahwa partisipasi suami kemungkinan tiga kali lebih besar terhadap kepatuhan ibu memeriksakan kehamilannya dibandingkan dengan suami yang tidak berpartisipasi. 


\section{METODE PENELITIAN}

Desain pada penelitian adalah strategi untuk mencapai tujuan penelitian yang telah dietetapkan dan digunakan sebagai pedoman atau penuntun peneliti pada seluruh proses penelitian. Penelitian ini menggunakan penelitian observasional. Rancangan yang dipakai pada penelitian survei sampel ini termasuk cross sectional analitik menggunakan pendekatan kuantitatif yaitu melakukan pengukuran atau pengamatan pada variabel bebas (independent) dengan variabel tergantung (dependent) dilakukan dalam waktu yang sama, Subyek pada penelitian ini adalah seluruh ibu hamil yang melakukan ANC ke polindes yang memiliki program kelas ibu hamil di Puskesmas turi tahun 2019 sejumlah 382 Ibu Hamil. Sampel untuk penelitian ini merupakan Semua ibu hamil dengan umur kehamilan >20 minggu yang melakukan ANC ke wilayah kerja Puskesmas Lamongan yang memiliki program kelas ibu hamil pada bulan April sampai dengan Mei 2019 dan bersedia untuk diberi pertanyaan. jumlah responden sebanyak 110 responden. Untuk teknik sampling pada penelitian ini menggunakan Simple Random sampling, Variabelvariabel yang diteliti meliputi variabel tergantung yaitu pelaksanaan kelas Ibu hamil dan variabel bebas yaitu Petugas kesehatan, sarana prasarana, motivasi Ibu, Dukungan emosional dan Pengetahuan Ibu , Keseluruhan variabel dibuat standarisasi dengan pemberian kode di setiap item pertanyaan data diolah dan dianalisis secara univariat, bivariat dan multivariat dengan menggunakan uji regresi logistic.

\section{HASIL PENELITIAN}

Hasil analisis regresi menunujukan nilai probabilitas sebagai berikut: Variabel dukungan suami diperoleh nilai p-value sebesar $0,000<\alpha=0,05$, sehingga $\mathrm{H}_{0}$ ditolak dan $\mathrm{H}_{1}$ diterima. Maka kesimpulan yang diambil adalah variabel dukungan suami berpengaruh terhadap pelaksanaan kelas ibu hamil di wilayah kerja Puskesmas Turi tahun 2019.

\section{PEMBAHASAN}

Berdasarkan hasil analisis pvalue sebesar $0,000<\alpha=0,05$, sehingga $\mathrm{H}_{0}$ ditolak dan $\mathrm{H}_{1}$ diterima. Maka kesimpulan yang diambil adalah variabel dukungan suami berpengaruh terhadap pelaksanaan kelas ibu hamil di wilayah kerja Puskesmas kota Lamongan. Dukungan sosial didefinisikan sebagai pertukaran sumber daya yang terdiri dari pemberi dan penerima dengan maksud untuk meningkatkan kesejahteraan penerima. Ciri-ciri bentuk dukungan sosial berkaitan dengan komposisi jaringan sosial atau sumber-sumber dukungan, dimana karakteristik fungsionalnya ditandai dengan penyediaan sumber daya tertentu atau jenis dari dukungan (Cohen et al., 2010). Dukungan sosial memiliki kekuatan sebagai pencegahan atau dapat mendorong seseorang berperilaku sehat. Cohen dan Wills dalam Cohen et al (2010) menganalisa beberapa teori yang mendukung hipotesis bahwa dukungan sosial (social support) berdampak pada kesehatan dan kesejahteraan. 
Dukungan sosial adalah sumber daya yang diberikan orang lain. Dukungan sosial ini perlu diperhatikan mulai dari masa anak-anak sampai dewasa. Dukungan dapat memberikan perubahan perilaku dan karekteristik emosional, karena dapat membuat orang untuk menghentikan sesuatu yang telah mereka lakukan atau melakukan sesuatu yang belum pernah mereka lakukan sebelumnya.

Sumber dukungan sosial antara lain; pasangan, keluarga dan masyarakat. Dukungan sosial yang paling dekat dengan ibu hamil adalah dari pasangannya (suami). Dukungan (motivasi) atau dukungan suami berperan sangat besar dalam menentukan status kesehatan ibu. Jika suami mengharapkan adanya kehamilan, maka memperlihatkan dukungannya dalam berbagai hal akan mempengarhui ibu menjadi lebih percaya diri, lebih bahagia, menunjukkan kesiapan dan lebih kuat secara mental untuk menghadapi segala hal kehamilan, persalinan dan masa nifas. Keterlibatan anggota keluarga atau orang terdekat dapat membantu terjadinya perubahan untuk berperilaku ke arah hidup sehat dan mampu meningkatkan kesadaran untuk berubah (Sarafino \& Smith, 2014).

Dalam penelitian Mullany et al. (2007) dan Fatimah (2009) juga memiliki pendapat yang serupa bahwa dukungan dari keluarga terutama suami dalam mengikuti kelas ibu hamil sangat berpengaruh besar pada ibu hamil. Masyarakat yang kurang pengetahuan tentang kelas ibu hamil cenderung tidak mendukung kegiatan kelas ibu hamil dan masyarakat masih menganggap kelas ibu hamil itu merupakan pekerjaan orang kesehatan saja, sehingga hal tersebut akan mempengaruhi partisipasi ibu dalam kegiatan kelas ibu hamil.

Hasil dari beberapa penelitian tersebut juga sesuai dengan konsep yang dinyatakan oleh Mullany et al., (2007) bahwa keluarga atau orang terdekat merupakan perantara yang efektif dan mampu memberikan kemudahan seseorang untuk mendapatkan pelayanan kesehatan. Karena keluarga terutama suami juga memiliki peran dalam menentukan keputusan untuk memelihara kesehatan para anggota keluarganya.

Dukungan dari suami dan hubungan yang baik dapat memberikan kontribusi penting pada kesehatan ibu. Dukungan sosial yang dibutuhkan adalah berupa dukungan secara emosional yang mendasari tindakan. Hal tersebut akan membuat orang merasa diperhatikan, dicintai, dimuliakan dan dihargai. Menurut Cohen dalam Sayem et al., (2011) bahwa dukungan secara psikologis yang diterima seseorang meliputi; informasi, nasehat verbal dan non verbal, bantuan nyata berupa kehadiran mereka sehingga berpengaruh terhadap emosional.

Dukungan sosial dapat berpengaruh terhadap penilaian individu dalam memandang seberapa berat suatu peristiwa yang terjadi dalam hidupnya, kemudian dapat mempengaruhi pilihan dalam upaya penanggulangan, serta dukungan sosial juga dapat berdampak langsung terhadap perilaku kesehatan. Ibu lebih mudah terpengaruh untuk melakukan perilaku kesehatan yang positip 
manakala mereka mendapat dukungan yang memadai dibandingkan suami (Montigny et al., 2006). Hal ini dibuktikan penelitian Nursito (2007) bahwa partisipasi suami kemungkinan tiga kali lebih besar terhadap kepatuhan ibu memeriksakan kehamilannya dibandingkan dengan suami yang tidak berpartisipasi.

Beberapa penelitian tentang dukungan sosial suami antara lain hasil penelitian Elsenbruch et al. (2007); Spoozak et al. (2010); Liu et al. (2013) menyebutkan bahwa dukungan sosial suami sangat berhubungan positif dengan kesehatan mental dan fisik ibu selama menjalani masa kehamilan dan persalinan. Hasil penelitian Kungwimba et al. (2013) dan Negron et al. (2014) menunjukkan bahwa dukungan sosial juga berperan penting selama masa nifas ibu dan penelitian Feldman et al. (2000) menunjukkan dukungan sosial berpengaruh terhadap perawatan bayinya. Dukungan sosial suami yang tinggi akan berpengaruh terhadap perilaku ibu dalam pemberian ASI eksklusif hal ini dibuktikan oleh penelitian Rokhanawati (2009). Penelitian serupa mengenai

Dukungan sosial suami pada hasil penelitian Rachmadahniar (2005) menunjukkan bahwa dukungan sosial suami pada wanita dimana secara signifikan dukungan sosial mempengaruhi emosi wanita dalam program skrining kanker leher rahim. Terbukti bahwa dukungan sosial sangat tinggi dibutuhkan untuk menurunkan beratnya beban psikologis seseorang karena dapat mengurangi stress dan dampak negatif dari kejadian buruk yang dialami seseorang dalam hidupnya.

Jadi dapat disimpulkan bahwa dukungan sosial adalah segala bentuk tindakan dan ucapan yang bersifat membantu dengan melibatkan emosi, informasi, instrumentasi dan appresiasi (penilaian positip) pada individu dalam menghadapi masalahnya. Dukungan suami yang dimaksud dalam penelitian ini adalah dukungan psikologis yang diberikan suami terhadap isteri baik secara fisik maupun psikis dimana suami ada pada saat dibutuhkan dan dapat memberikan bantuan secara psikologis baik berupa motivasi, perhatian, penerimaan atau dengan cara mencurahkan segenap hati, perasaan dan pikiran dengan jujur sesuai harapan ibu untuk lebih dicintai, diperhatikan dan dihargai

Pendekatan baru dalam meningkatkan dukungan suami terhadap ibu adalah mengikutsertakan mereka dalam setiap program upaya peningkatan kehadiran ibu. Pada kenyataannya pria/ suami merupakan partner yang potensial untuk mencapai tingkat kesehatan yang lebih baik. Minimal satu kali pertemuan ibu hamil di damping suami/keluarga. Hal ini dimaksudkan agar kesehatan ibu selama hamil, bersalin, nifas, termasuk kesehatan bayi yang baru dilahirkan dan kebutuhan akan KB pasca persalinan menjadi perhatian dan tanggung jawab seluruh keluarga . Salah satu peran serta suami dalam kehadiran ibu melakukan kelas ibu hamil yaitu dengan memberikan motivasi kepada ibu berupa dukungan secara psikologis dan dukungan nyata terhadap ibu agar dapat berpartisipasi dalam program kelas ibu hamil. 


\section{KESIMPULAN}

Ada pengaruh dukungan suami dengan pelaksanaan kelas ibu hamil di puskesmas Turi kabupaten Lamongan dan Diharapkan kepada ibu hamil untuk membaca buku KIA yang diberikan tenaga kesehatan pada saat pemeriksaan kehamilan, karena terdapat informasi yang penting tetang bagaimana memelihara dan merawat kesehatan, medeteksi lebih dini masalah selama kehamilan dan Ibu hamil lebih proaktif mencari informasi tentang manfaat pelaksaan kelas ibu hamil dimana informasi tersebut dapat di dapatkan melalui tenaga kesehatan, sosial media seperti televisi sehingga ibu termotivasi untuk mengikuti pelaksanaan kelas ibu hamil

\section{DAFTAR PUSTAKA}

Ana Wigunantiningsih. 2014. Indeks kepuasan Ibu hamil berdasarkan faktor - faktor yang mempengaruhi pelayanan kelas ibu hamil. Universitas Diponegoro

Azwar . (2008). Riset Kesehatan Dasar (p. 178). Jakarta.

Jawa Timur, P. (2014). Upah Minimum Kabupaten/Kota di Lamongan Tahun 2014. Peraturan Gubernur Jawa Timur Tanggal 21 Nopember 2014 No.69 Tahun 2014 Tentang Upah Minimum Kabupaten/Kota.

Croydon, D. (2008). Qualitative Evaluation Study of Teenage
Antenatal Classes and an Evaluation Review of Teenage Parent Support Groups Provided in Croydon Contents. Croydon Primary Care Trust, 1-35.

Depkes RI. (2010). KIE Safe Motehrhood di Indonesia. Jakarta: Departemen Kesehatan RI.

Depkes RI. (2008). Panduan Pelaksanaan Strategi Making Pregnancy Safer (MPS) and Child Survival. Jakarta: Departemen Kesehatan RI.

Depkes RI. (2009). Pegangan Fasilitator Kelas Ibu Hamil Tahun 2009. In Pegangan Fasilitator Kelas Ibu Hamil (p. 72). Jakarta: Departemen Kesehatan RI.

Dinkes, B. (2014). Profil Kesehatan Provinsi Jawa Timur 2014. Jawa Timur.

Dinkes, D. (2014). Profil Kesehatan Kota Lamongan Tahun 2014. Lamongan.

Desi Wijayanti eko, 2014. Faktorfaktor yang mempengaruhi implementasi program kelas ibu hamil oleh bidan desa di kab kendal. Universitas Diponegoro. 
Hastuti, P. S., Nugroho, H., \& Usnawati, N. (2011). Efektifitas Pelatihan Kelas Ibu Hamil untuk Meningkatkan Pengetahuan, Sikap, Keterampilan dan Kunjungan Antenatal Care. Jurnal Penelitian Kesehatan Suara Forikes, 2, 122-134.

Julianto, E. (2009). Faktor-faktor yang mempengaruhi keputusan memilih penolong persalinan di Kecamatan Babul Rahmah Kabupaten Aceh Tenggara Tahun 2008. Universitas Sumatera Utara.

Kemenkes RI. (2011). Pedoman Pelaksanaan Kelas Ibu Hamil Tahun 2011. In Buku Pedoman Pelalaksanaan Kelas Ibu hamil (pp. 1-26). Jakarta.

Kemenkes RI. (2013). Situasi Keluarga Berencana di Indonesia. In Buletin Jendela Data dan Informasi Kesehatan (p. 14). Jakarta: Kementerian Kesehatan Republik Indonesia.

Kependudukan, B., \& Nasional, B. (2013). Survei Demografi dan Kesehatan Indonesia. SDKI.

Kusbandiyah, J. (2013). Analisis Implementasi Program Kelas Ibu Hamil oleh Bidan Puskesmas di Kota Malang. Universitas Diponegoro.
Longman . (2007). Bunga Rampai Obstetri dan Gynekology Sosial. Jakarta: Yayasan Bina Pustaka Sarwono

Mullany, B. C., Becker, S., \& Hindin, M. J. (2007). The impact of including husbands in antenatal health education services on maternal health practices in urban Nepal : results from a randomized controlled trial. Oxford University, 22(2), 166- 176.

Mulyanti, L., Mudrikatun, \& S. (2010). Hubungan Dukungan Suami Pada Ibu Hamil Dengan Kunjungan ANC Di Rumah Bersalin Bhakti IBI Kota Semarang. Jurnal Unimus, 2732.

Nichols, M. R. (2007). Adjustment to New Parenthood: Attenders versus Nonattenders at Prenatal Education Classes. Perinatal Care, Georgetown University, Washington, D.C., 22(1), 21-26.

Ni Ketut Nopi Wiantari, ( 2015 ) Hubungan karakteristik ibu dan dukungan sosial suami dengan partisipasi ibu mengikuti pelaksanaan kelas ibu hamil. Universitas Udaya

Osninelli. (2007). Hubungan pendidikan prenatal melalui kelas ibu hamil dengan persalinan tenaga kesehatan di Kabupaten Tanah Datar Sumatera Barat. Universitas Gajah Mada Yogyakarta. 
Purwarini, D. (2012). Pengaruh Kelas Ibu hamil terhidap Pengetahuan dan Sikap Ibu dalam Kehamilan dan Persalinan di wilayah Puskesmas Gurah Kabupaten Kediri. Universitas Sebelas Maret, Surakarta.

Redshaw, M., \& Henderson, J. (2013). Fathers, engagement in pregnancy and childbirth : evidence from a national survey. BMC Pregnancy and Childbirth, 13(70), 1-15.

Sarafino, E. P., \& Smith, T. W. (2014). Health psychology biopsychological interaction (8th ed.). New York: Wiley.

Simanjuntak, T. (2008). Faktor-faktor yang berhubungan dengan kelengkapan pemeriksaan kehamilan $K 4$ di Puskesmas Kecamaan Pakuaji Tahun 2003. Universitas Indonesia.

Yanti, H. P. (2013). Evaluasi Program Kelas Ibu hamil di Puskesmas Wilayah Kabupaen Batang Tahun 2012. Universitas Diponegoro. 